\title{
AVALIAÇÃO DA RESISTÊNCIA DO EUCALIPTO À MURCHA-BACTERIANA CAUSADA POR Ralstonia solanacearum ${ }^{1}$
}

\author{
Reginaldo Gonçalves Mafia², Acelino Couto Alfenas ${ }^{3}$ e Maria Alves Ferreira ${ }^{4}$
}

\begin{abstract}
RESUMO - O plantio de clones de eucalipto resistentes constitui a principal estratégia para o controle de doenças no campo. Assim, este trabalho objetivou testar métodos de inoculação de Ralstonia solanacearum visando selecionar eucalipto resistente à murcha-bacteriana. Os métodos de inoculação foram selecionados em função da facilidade operacional e testados na avaliação de quatro clones (híbridos E. urophylla x E. grandis): i) aplicação de $5 \mathrm{~mL}$ de inóculo $\left(10^{8} \mathrm{ufc} / \mathrm{mL}\right)$ na região do coleto de mudas; ii) aplicação de $5 \mathrm{~mL}$ de inóculo $\left(10^{8} \mathrm{ufc} / \mathrm{mL}\right)$ na região do coleto de mudas após o ferimento do sistema radicular; iii) corte de 1/3 basal do sistema radicular e imersão das raízes por 1 min em suspensão de inóculo na mesma concentração; e iv) condução de mudas transplantadas em infectário, constituído de canaletões com areia infestada quinzenalmente (taxa de $\left.0,25 \mathrm{~L} / \mathrm{m}^{3}\right)$ com suspensão bacteriana $\left(10^{8} \mathrm{ufc} / \mathrm{mL}\right)$ e submetidas a coletas de brotações, de forma similar ao que é feito em minijardins comerciais. A condução das mudas em infectário apresentou maiores incidências de doença (exsudação de pus bacteriano), variando de 81 a 100\%. O segundo experimento objetivou avaliar a resistência de diferentes espécies de eucalipto, empregando-se o método de transplantio das mudas para o infectário. A avaliação da infecção pela presença de exsudação bacteriana apresentou resultados mais consistentes para comparação dos genótipos. A intensidade da murcha-bacteriana foi afetada pelas condições da planta e do ambiente. Todas as espécies exibiram sintomas da doença, porém E. tereticornis e E. grandis apresentaram, respectivamente, o menor (33,3\%) e o maior (91,7\%) percentual de genótipos infectados (suscetíveis). Os resultados deste trabalho são importantes ferramentas (método de inoculação) e fontes (espécies de eucalipto) de resistência para o controle da murcha-bacteriana do eucalipto.
\end{abstract}

Palavras-chave: Resistência; Melhoramento genético; Controle de doenças.

\section{EUCALYPTUS RESISTANCE EVALUATING TO BACTERIAL WILT CAUSED BY Ralstonia solanacearum}

\begin{abstract}
The use of resistant eucalyptus clones is the most important strategy to disease control on the field. Thus, this work aimed to evaluated methods of Ralstonia solanacearum inoculation in order to select eucalyptus resistant to bacterial wilt. The inoculation methods were selected due to ease of operation and tested in order to evaluate four clones (hybrids $\boldsymbol{E}$. urophylla $x$ E. grandis): i) application of $5 \mathrm{~mL}$ pathogen inoculum $\left(10^{8} \mathrm{cfu} / \mathrm{mL}\right)$ on the root collar of seedlings; ii) application of $5 \mathrm{~mL}$ of pathogen inoculum $\left(10^{8}\right.$ $c f u / m L)$ on the root collar of seedlings after wound of the radicular system; iii) cut of 1/3 basal of the radicular system and immersion of the roots into pathogen inoculum, at the same concentration, for 1 min; and iv) conduction of seedlings transplanted to infested sand maintained in container with application at 15 days intervals (rate of $0.25 \mathrm{~L} / \mathrm{m}^{3}$ ) and bacterial suspension $\left(10^{8} \mathrm{cfu} / \mathrm{mL}\right.$ ) and submitted to collection of sprouting, similarly as it is done in commercial clonal mini-garden. The seedlings transplant to infected sand presented a higher incidence of the disease (bacterial exudation), ranging from 81 to 100\%. The second trial aimed to evaluate resistance of different eucalyptus species, using the method of transplanting seedlings to the infected sand. The evaluation of the infection by exudation bacterial method was more appropriate to compare the genotypes. The bacterial wilt intensity was affected by plant and environment conditions. Every species showed
\end{abstract}

\footnotetext{
${ }^{1}$ Recebido em 02.12.2012 aceito para publicação em 05.06.2014

${ }^{2}$ FIBRIA CELULOSE S.A., FIBRIA, Brasil. E-mail: <rgoncalves@fibria.com.br>.

${ }^{3}$ Departamento de Fitopatologia, Universidade Federal de Viçosa, UFV, Brasil. E-mail: <aalfenas@ufv.br>.

${ }^{4}$ Departamento de Fitopatologia, Universidade Federal de Lavras, UFLA, Brasil. E-mail: <mariaferreira@dfp.ufla.br>.
} 
disease symptoms, but E. tereticornis and $\mathbf{E}$. grandis showed, respectively, the lowest (33.3\%) and the highest (91.7\%) percentage of infected genotypes (susceptible). The results of this work are important tools (inoculation method) and resistance sources (eucalyptus species) to bacterial wilt disease control in eucalyptus.

Keywords: Protocol; Genetic Breeding; Disease control.

\section{INTRODUÇÃO}

A murcha-bacteriana do eucalipto, causada por Ralstonia solanacearum (YABUUCHI et al., 1995), é uma doença com alto potencial de causar danos à cultura, sobretudo por se tratar de um patógeno bacteriano cosmopolita, extremamente variável, vascular e que se associa ao sistema radicular de várias plantas cultivadas e daninhas, em regiões tropicais e subtropicais do mudo (LOPES; TAKATSU, 1997; LOPES, 1994). A bactéria causa doença em mais de 200 espécies de plantas, englobando aproximadamente 50 famílias botânicas (HAYWARD, 2000). A gama de hospedeiros inclui a maioria das solanáceas, leguminosas, monocotiledôneas e várias espécies arbóreas.

A murcha-bacteriana do eucalipto foi relatada, pela primeira vez, no início da década de 1980 (SUDO et al., 1983). Além do Brasil, a doença já foi constatada nas principais regiões eucaliptocultoras mundiais, como China, Taiwan, Indonésia, Austrália, Venezuela e África do Sul (COUTINHO et al., 2000). Na China, E. urophylla Blake, E. tereticornis Smith, E. camaldulensis Dehnh. e híbridos de E. grandis Hill ex Maiden $x$ E. urophylla ou E. urophylla x E. grandis têm sido os materiais mais suscetíveis. Em condições de infecção natural, E. grandis, E. pellita F. Muell., E. propinqua Deane \& McKie e E. saligna Smith são as espécies mais suscetíveis (WU; LIANG, 1988).

No Brasil, vários estudos foram desenvolvidos no sentido de desenvolver métodos de inoculação e seleção de genótipos de eucalipto resistentes à murchabacteriana (DIANESE et al., 1990; COUTINHO et al., 2000). Todavia, a utilização desses métodos raramente permite causar as infecções bacterianas e a reprodução dos sintomas da doença, o que dificuldade a realização de estudos de etiologia e resistência (FEREIRA et al., 2006; ALFENAS; MAFIA, 2007; XAVIER et al., 2007). Desse modo, testaram-se métodos de inoculação do patógeno e alternativas para reprodução dos sintomas da doença. Além disso, foram avaliadas as principais espécies de eucalipto quanto ao nível de resistência à murcha-bacteriana, visando identificar fontes de resistência para o controle da doença no Brasil.

\section{MATERIAL E MÉTODOS}

\subsection{Monitoramento das condições climáticas}

Os experimentos foram realizados entre início de setembro até final de dezembro de 2005, em função das condições climáticas mais favoráveis ao patógeno. O monitoramento das condições climáticas foi realizado diariamente, em intervalos de $30 \mathrm{~min}$, para temperatura e umidade relativa do ar, com o auxílio de um coletor automático de dados (Modelo CR-10X, Campbell Scientific Inc. Logan, UT, USA).

\subsection{Isolado do patógeno e preparo do inóculo}

Empregou-se o isolado UFV 34 de $R$. solanacearum, obtido de E. grandis, proveniente da região de Eunápolis, Bahia. Para produção de inóculo da bactéria, realizou-se a multiplicação inicial do patógeno a partir de culturas mantidas em água destilada esterilizada. $\mathrm{O}$ isolado foi selecionado em meio de Kelman com cloreto de tetrazólio (KELMAN, 1954) e caracterizado, previamente, como pertencente a biovar 1 (HAYWARD, 1991). Amultiplicação da bactéria foi realizada em meio sólido de Kado e Heskett (1970) a $28^{\circ} \mathrm{C}$, no escuro. Após 24 h de incubação, procedeu-se à raspagem das colônias em solução salina ( $\mathrm{NaCl}$ a 0,85\%) e com o auxílio de uma alça de Drigalski. A concentração de inóculo foi ajustada, por espectrofotometria $\left(\mathrm{OD}_{540}=0,2 \mathrm{Abs}\right)$, para $10^{8} \mathrm{ufc} / \mathrm{mL}$.

\subsection{Produção das mudas de eucalipto}

As mudas clonais e seminais foram produzidas em tubetes de $55 \mathrm{~cm}^{3}$ de capacidade, com substrato composto de casca de arroz carbonizada, vermiculita de granulometria média e substrato comercial (MecPlant $\left.^{\circledR}\right)$ (1:1:1). As mudas de eucalipto foram inoculadas ou transplantadas para o infectário com 60 dias de idade.

\subsection{Avaliação dos métodos de inoculação em clones de eucalipto}

Foram testadas três formas de inoculação em mudas mantidas em tubetes, além do método de inoculação por infecção natural em infectário. Esses métodos foram testados para inoculação de quatro clones de eucalipto 
(híbridos E. urophylla x E. grandis), como se segue: i) aplicação de $5 \mathrm{~mL}$ de inóculo $\left(10^{8} \mathrm{ufc} / \mathrm{mL}\right)$ na região do coleto de mudas; ii) aplicação de $5 \mathrm{~mL}$ de inóculo $\left(10^{8} \mathrm{ufc} / \mathrm{mL}\right)$ na região do coleto de mudas após o ferimento do sistema radicular com o auxílio de um estilete; iii) corte de 1/3 basal do sistema radicular e imersão das raízes por 1 min em suspensão de inóculo na mesma concentração; e iv) condução de mudas transplantadas em infectário, constituído de canaletões com areia infestada quinzenalmente, com suspensão bacteriana e submetidas a coletas de brotações, de forma similar ao que é realizado em minijardins comerciais. Esses métodos de inoculação foram escolhidos em função da facilidade operacional. O último método foi desenvolvido considerando experiências com culturas agronômicas e ajustado a partir das observações do primeiro relato da murcha-bacteriana em viveiros clonais de eucalipto (ALFENAS et al., 2006).

\subsection{Avaliação da resistência de espécies de eucalipto}

As mudas de eucalipto foram transplantadas para o infectário com 60 dias de idade, dispostas em ziguezague, com espaçamento de $10 \mathrm{~cm}$ entre plantas. Antes do plantio, removeu-se $1 / 3$ da porção basal do sistema radicular das mudas. Após o plantio, realizou-se diariamente uma fertirrigação com solução nutritiva composta por nitrato de cálcio (23,0 g/L), cloreto de potássio $(6,0 \mathrm{~g} / \mathrm{L})$, nitrato de potássio (3,5 g), monoamônio-fosfato (2,4 g/L), sulfato de magnésio (9,1 g/L), tenso ferro (1,3 g/L), ácido bórico (3,5 g/ $\mathrm{L})$, sulfato de zinco $(0,6 \mathrm{~g} / \mathrm{L})$, sulfato de manganês $(1,0$ $\mathrm{g} / \mathrm{L})$, sulfato de cobre $(0,125 \mathrm{~g} / \mathrm{L})$ e molibdato de sódio $(0,05 \mathrm{~g} / \mathrm{L})$. A solução nutritiva foi aplicada na proporção de $0,25 \mathrm{~L} / \mathrm{m}^{3}$ de areia. Aos 30 dias após o transplantio, realizou-se a poda apical das mudas de eucalipto visando à formação das minicepas e, subsequentemente, a cada 15 dias realizaram-se coletas de brotações, a fim de simular o manejo de minicepas praticado para a obtenção de miniestacas para enraizamento. Em experimento prévio, mudas de dois clones de eucalipto foram conduzidas com e sem podas da parte aérea, visando avaliar o efeito dessa operação sobre a ocorrência de infecções bacterianas.

O infectário foi construído com calhas de fibrocimento (Canalete 49, Eternit ${ }^{\circledR}$ ), de forma similar ao sistema de minijardim clonal empregado para propagação clonal de eucalipto. As calhas possuem dimensões de $181 \mathrm{~mm}$ de altura, largura variando de
191 (parte interna) a $490 \mathrm{~mm}$ (parte superior) e comprimento de $2.000 \mathrm{~mm}$. As calhas foram dispostas lateralmente sobre suportes de alvenaria (50 mm de altura), com inclinação negativa de 1\% em direção ao dreno, instalado no final da calha. O interior das calhas foi recoberto por filme plástico transparente, sob o qual foi adicionada uma camada de aproximadamente $5 \mathrm{~cm}$ de brita. Posteriormente, recobriu-se a camada de brita com tela sombrite (50\%) e, finalmente, sobre a tela sombrite completou-se o espaço disponível com areia previamente esterilizada (Figura 1). A população bacteriana no

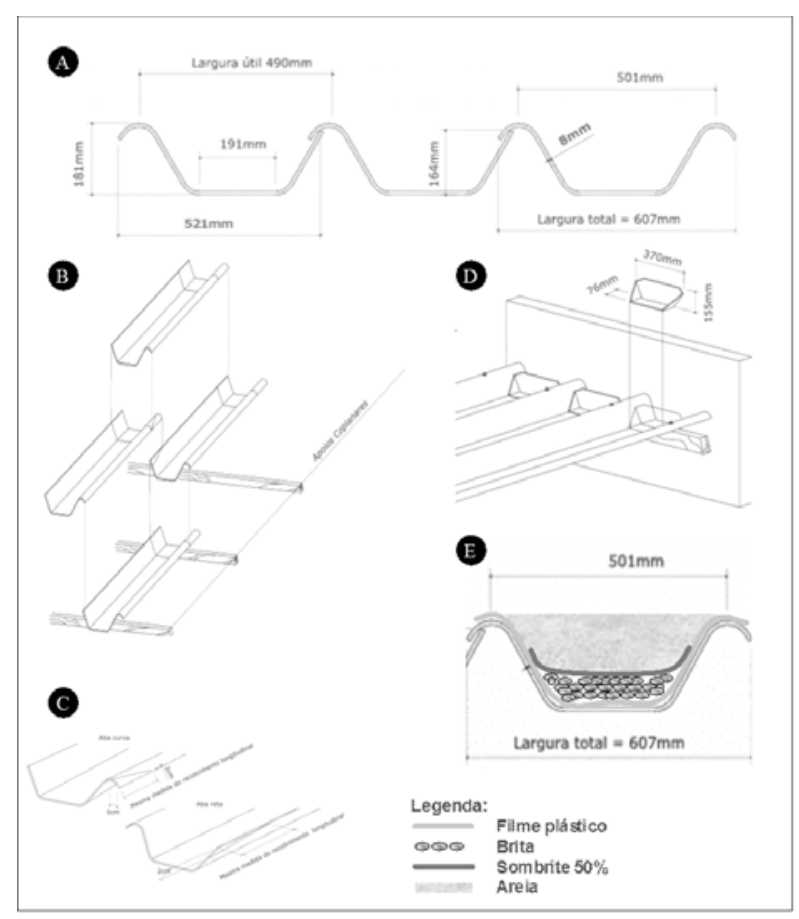

Figura 1 - Ilustração das calhas de cimento: A - Dimensões das calhas (181 mm altura x $490 \mathrm{~mm}$ largura $\mathrm{x}$ 200 m comprimento); B - Montagem lateral das calhas (sobre mureta de alvenaria de $500 \mathrm{~mm}$ de altura e inclinação 1\%); C - Detalhe dos encaixes laterais; D - Fechamento das extremidades; e E - Cobertura (filme plástico) e substrato (areia e brita separadas por sombrite $50 \%$ ) das calhas.

Figure 1- Illustration of the cement container: A - Dimension of the containers (181 $\mathrm{mm}$ height $\times 490 \mathrm{~mm}$ width x $200 \mathrm{~mm}$ length); B - Lateral mounting of the containers (support by wall $500 \mathrm{~mm}$ height and $1 \%$ inclination); C - Details of the lateral groove; $D$ - Edge closure; and E-Containers cover (plastic film) and substrate (sand and rocks separated by the plastic wire "sombrite" 50\%).

Revista Árvore, Viçosa-MG, v.38, n.4, p.649-656, 2014 
substrato do infectário foi mantida por infestações, realizadas em intervalos de 15 dias, com a suspensão de inóculo ajustada para $10^{8} \mathrm{ufc} / \mathrm{mL}$. A infestação foi realizada na proporção de $0,25 \mathrm{~L} / \mathrm{m}^{3}$ de areia.

\subsection{Material genético de eucalipto}

Os clones de eucalipto testados para comparar os métodos de inoculação foram: UFV 01, UFV 02, UFV 03 e UFV 04 (híbridos de E. urophylla x E. grandis), sabidamente com níveis diferenciados de resistência à doença. Para identificação de fontes de resistência, o melhor método de inoculação identificado anteriormente foi testado nas principais espécies de interesse florestal, incluindo E. grandis, E. saligna, E. globulus, E. urophylla, E. camaldulensis, E. tereticornis e E. dunnii.

\subsection{Avaliação das plantas inoculadas}

As plantas de eucalipto foram avaliadas quanto à presença de sintomas externos de murcha e morte das mudas inoculadas e por presença de infecções vasculares. Nesse último caso, a presença da bactéria nos tecidos vasculares foi confirmada por meio da avaliação microscópica de exsudação de pus bacteriano. Para isso, três fragmentos tissulares (aproximadamente $5 \times 5 \mathrm{~mm}$ ), retirados da região vascular, foram depositados em uma gota d’água destilada sobre uma lâmina microscópica. Posteriormente, os fragmentos foram observados ao microscópio de luz (40 e 100 X) e avaliados quanto à presença de exsudação de pus bacteriano.

\subsection{Delineamento experimental e análises estatísticas}

A comparação dos métodos de inoculação foi realizada, empregando-se, em cada clone de eucalipto, o delineamento inteiramente casualizado em classificação mista, com um tratamento adicional composto por quatro métodos de inoculação (três métodos de inoculação de mudas em tubetes e o método do infectário), além da testemunha. Em cada tratamento, foram realizadas cinco repetições constituídas de 16 plantas. Os dados foram submetidos à análise de variância (ANOVA), empregando-se o teste $\mathrm{F}$ a $5 \%$ de probabilidade. Posteriormente, a comparação entre as médias foi realizada por meio de análise de contrastes ortogonais. No segundo experimento, no qual se avaliou a resistência genética de diferentes espécies de eucalipto, foram utilizadas cinco repetições de 16 plantas por espécie avaliada. Posteriormente, as médias foram comparadas considerando o erro-padrão da média.

\section{RESULTADOS}

No período de realização dos experimentos, a amplitude térmica foi de $9{ }^{\circ} \mathrm{C}$, com temperatura mínima de 16 e máxima de $25^{\circ} \mathrm{C}$. O mês de outubro foi o mais quente dentro do intervalo monitorado, com média de $21,8^{\circ} \mathrm{C}$. A temperatura média foi de $21^{\circ} \mathrm{C}$, considerando todo o período. A umidade relativa do ar, na maior parte do tempo, foi superior a $80 \%$. A amplitude foi de 35\%, com mínima de 64 e máximo de 99\% de umidade. Menores valores de umidade relativa foram observados também no mês de outubro, em média de 78,7\% (Figura 2).

\subsection{Avaliação dos métodos de inoculação em clones de eucalipto}

Não houve correlação positiva entre plantas assintomáticas e ausência de infecções. Plantas aparentemente sadia e sem sintomas de murcha apresentavam, em muitos casos e independentemente do método de inoculação, presença de infecções bacterianas, constatadas pelo teste de exsudação de pus bacteriano.

Entre todos os métodos de inoculação selecionados pela facilidade operacional, o transplantio de mudas para o infectário resultou em maior incidência de mudas infectadas, independentemente do clone de eucalipto testado. Esse método de inoculação simula as condições ambientais e de estresse das plantas em minijardim clonal.

De forma geral, o método de inoculação por aplicação de inóculo na região do coleto não resultou em infecção. No clone UFV 04, a inoculação da bactéria

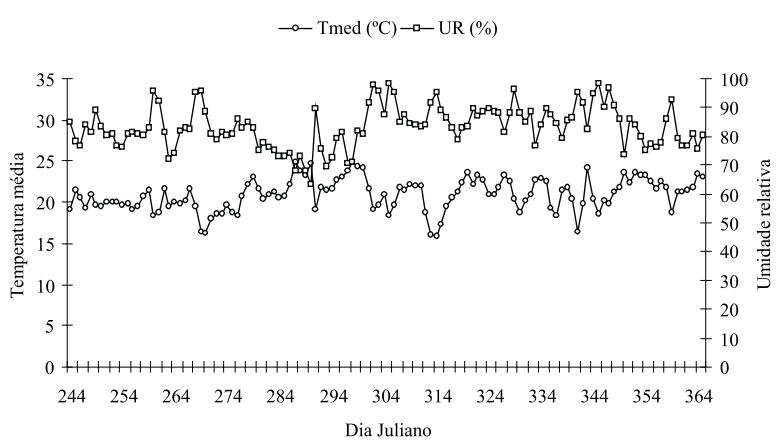

Figura 2 - Condições climáticas durante a realização dos experimentos: flutuação da temperatura $\left({ }^{\circ} \mathrm{C}\right)$ média (Tmed) e umidade relativa do ar (\%) diária.

Figure 2 - Climate conditions during the trials: Daily temperature fluctuation $\left({ }^{\circ} \mathrm{C}\right)$ average $($ Tmed) and air relative humidity (\%). 
após o ferimento do coleto resultou em maior incidência de plantas infectadas (exsudação positiva de 50\%) entre os métodos de inoculação em plantas mantidas em tubetes. No transplantio das mudas desse mesmo clone para o infectário, todas as plantas foram infectadas pelo patógeno, conforme comprovado pelo resultado positivo para exsudação bacteriana (Tabela 1).

\subsection{Avaliação da resistência de espécies de eucalipto}

De forma similar ao observado nas mudas clonais, não houve correlação entre ausência do sintoma de murcha e sanidade das plantas das diferentes espécies testadas. As mudas sabidamente infectadas pelo patógeno, de acordo com o teste positivo para exsudação de pus bacteriano, em muitos casos não murcharam e permaneceram vivas durante todo o período. Entretanto, todas as plantas infectadas e que morreram durante o experimento passaram por um estágio intermediário de murcha.

A mortalidade de plantas das espécies E. dunnii, E. grobulus e E. urophylla foi correlacionada com a ocorrência de infecção de $R$. solanacearum. Todavia, plantas que não morreram também apresentavam infecções bacterianas. Entre as espécies, E. grandis destacou-se por apresentar a maior quantidade de genótipos suscetíveis. No entanto, E. tereticornis apresentou o menor percentual de genótipos infectados pelo patógeno (Tabela 2).

\section{DISCUSSÃO}

As condições climáticas observadas durante a realização dos experimentos não foram limitantes do estabelecimento da doença, considerando-se as condições ideais para o patógeno e, sobretudo, os altos níveis de infecção observados em determinadas combinações de métodos e genótipos inoculados.

Na primeira fase do trabalho, avaliaram-se diferentes métodos de inoculação do patógeno, empregando-se quatro clones de eucalipto. De forma geral, as inoculações realizadas em mudas contidas em tubetes não foram eficientes para causar as infecções e reprodução do sintoma de murcha. Entretanto, o transplantio das mudas para o infectário permitiu maior intensidade de infecção.

Tabela 1 - Incidência de Ralstonia solanacearum para clones de eucalipto em diferentes métodos para reprodução dos sintomas da doença.

Table 1 - Incidence of Ralstonia solanacearum to eucalyptus clones in different methods to reproduction disease symptoms.

\begin{tabular}{lcccc}
\hline Método de inoculação & \multicolumn{3}{c}{ Clone } \\
\cline { 2 - 5 } & UFV 01 & UFV 02 & UFV 03 & UFV 04 \\
\hline Aplicação do inóculo na região do coleto & 0,0 & 0,0 & 0,0 & 0,0 \\
Imersão de 2/3 das raízes no inóculo & 0,0 & 0,0 & 18,8 & 12,5 \\
Ferimento do coleto e aplicação do inóculo & 0,0 & 0,0 & 12,5 & 50,0 \\
Média dos três métodos de inoculação & 0,0 & 0,0 & 10,4 & 20,8 \\
Infecção de mudas em infectário & $93,8^{*}$ & $81,3^{*}$ & $87,5^{*}$ & $100^{*}$ \\
\hline
\end{tabular}

*Médias de incidência de infecções bacterianas estaticamente diferentes, por análise de contraste, em relação à média dos demais métodos de inoculação.

*Incidence average of infection statistically different, by contrast analysis, compared the average of other inoculation methods.

Tabela 2 - Incidência da doença (\%) nas espécies de eucalipto.

Table 2 - Disease incidence (\%) to eucalyptus species.

\begin{tabular}{|c|c|c|c|c|}
\hline Espécie & Procedência & Mortalidade (\%) & Genótipos infectados (\%) & Classificação* \\
\hline E. camaldulensis & MG & 0,0 & $62,5 \pm 2,76$ & $\mathrm{~S}$ \\
\hline E. dunnii & PR & $8,3 \pm 1,67$ & $64,6 \pm 4,00$ & S \\
\hline E. globulus & PR & $8,3 \pm 1,67$ & $64,6 \pm 3,16$ & S \\
\hline E. grandis & BA & 0,0 & $91,7 \pm 1,72$ & AS \\
\hline E. saligna & BA & 0,0 & $52,1 \pm 4,34$ & S \\
\hline E. tereticornis & BA & 0,0 & $33,3 \pm 1,72$ & MR \\
\hline
\end{tabular}

*Classificação das espécies: AS - altamente suscetível; S - suscetível; e MR - moderadamente resistente, com base na frequência de genótipos infectados (com presença de exsudação bacteriana).

*Species classification: AS - most susceptible; S-susceptible; e MR-moderated resistance, as function of the frequency disease susceptibly genotypes (bacterial exudation). 
O sistema de infectário desenvolvido neste trabalho difere do normalmente preconizado para inoculação de Ralstonia solanacearum, que em geral é montado na forma de canteiros de alvenaria contendo solo infestado artificialmente com o patógeno (GAVA et al., 2002; ARAÚJO et al., 2005). Autilização de areia como substrato, aliado a fertirrigações, estabelece condições mais favoráveis para o estabelecimento e multiplicação do patógeno, principalmente em razão da manutenção de maior temperatura, disponibilidade de água e de nutrientes. Além disso, observou-se que a realização das coletas frequentes de brotações favoreceu a ocorrência das infecções bacterianas, em razão da mortalidade de raízes. Essas condições são fundamentais para o estabelecimento, multiplicação e infecções da bactéria em condições naturais em minijardins clonais de eucalipto, conforme observado por Alfenas et al. (2006).

A expressão do sintoma de murcha em eucalipto, conforme observado no infectário, depende da intensidade de colonização e, fundamentalmente, das condições de ambiente e, ou, da debilitação das plantas. Após a coleta de brotações, observou-se que algumas plantas com sintoma de murcha se recuperavam, com emissão de novas brotações. Além disso, ocorreu maior intensidade de murcha nos ramos mais próximos do coleto. Tais brotações apresentavam intensa exsudação de pus bacteriano, em contraste com as brotações colhidas em porções mais altas da mesma planta.

Métodos de seleção de genótipos resistentes à murcha-bacteriana foram também desenvolvidos por Dianese e Dristig (1993). Esses autores estabeleceram que inoculações com suspensão de inóculo ajustada para $10^{6} \mathrm{ufc} / \mathrm{mL}$, em plantas de eucalipto com 10-12 pares de folhas expandidas, por meio de injeção do inóculo $(10 \mathrm{~mL})$ nas axilas foliares, foram mais consistentes para expressão dos sintomas de murcha e de morte.

Conforme os dados obtidos, selecionou-se o uso do infectário como método adequado para favorecer as infecções bacterianas. A avaliação da resistência à murcha-bacteriana por esse método apresentou algumas vantagens em relação à inoculação em plantas mantidas em tubetes. Entre elas, pode-se citar: maior percentual de infecção, maior facilidade de operacionalização e possibilidade de multiplicar os genótipos ao mesmo tempo que se realiza a avaliação da resistência, o que confere ao método a característica de não ser totalmente destrutivo. Entretanto, para manter o infectário são necessários maiores cuidados relativos à fertirrigação e coleta de brotações.

A temperatura é um dos principais fatores ambientais que interferem na interação patógeno-hospedeiro. Temperaturas mais elevadas favorecem o desenvolvimento do sintoma de murcha-bacteriana, em condições de campo, bem como para sobrevivência de $R$. solanacearum no solo. Para esse patógeno, quando adaptado em regiões tropicais, estima-se que a temperatura ótima oscila entre 25 e $35^{\circ} \mathrm{C}$ (TAKATSU; LOPES, 1997). Neste estudo, durante a realização dos experimentos, a temperatura média diária variou de 15 a $25^{\circ} \mathrm{C}$, enquanto a umidade relativa do ar foi superior a $80 \%$, na maior parte do período. Essas condições climáticas predominantes podem explicar a falta do desenvolvimento do sintoma de murcha, mesmo quando ocorreu colonização dos tecidos.

Constataram-se variações quanto à frequência de genótipos infectados, dependendo da espécie de eucalipto inoculada, conforme também previamente foi observado em vários trabalhos (DIANESE et al., 1990; LIN et al., 1996; LI; WU, 1996; SHI et al., 2000). Entre as espécies avaliadas, E. tereticornis destacou-se por apresentar a menor frequência de genótipos infectados. Em trabalhos futuros, torna-se necessário avaliar a estabilidade da resistência, considerando diferentes isolados e biovares do patógeno (COUTINHO et al., 2000). Como se sabe, o uso da resistência de plantas para o controle da murcha-bacteriana, tanto para espécies agrícolas quanto florestais, é extremamente difícil. A alta variabilidade na população do patógeno, as interações com fatores abióticos e bióticos do ambiente e a variabilidade quanto à agressividade de isolados locais de $R$. solanacearum afetam a severidade da doença e, possivelmente, a estabilidade da resistência (PRIOR; STEVA, 1990; DARRASSE et al., 1998; COELHO NETO et al., 2003). Esses fatores devem ser considerados para maior assertividade na determinação da resistência a essa doença pelo método selecionado neste trabalho.

Analogamente ao encontrado por Li e Wu (1996), constatou-se que E. grandis apresentou o maior percentual de plantas infectadas pelo patógeno. Na China, híbridos interespecíficos de E. grandis mostram-se altamente suscetíveis (LIN et al., 1996; SHI et al., 2000). No Brasil, ainda não existem avaliações para a maioria 
dos clones comerciais. Todavia, como esses materiais genéticos plantados atualmente têm como base populações de E. grandis, existe grande risco de suscetibilidade à murcha-bacteriana.

\section{CONCLUSÕES}

Neste trabalho, desenvolveu-se uma nova concepção de infectário para $R$. solanacearum, a qual permitiu avaliar e selecionar genótipos de eucalipto resistentes à murcha-bacteriana. Há variação para resistência inter e intraespecífica. Entre as espécies avaliadas, E. tereticornis foi uma das melhores fontes de resistência à doença.

\section{REFERÊNCIAS}

ALFEnAS, A. C.; MAFIA, R. G. Métodos em fitopatologia. Viçosa, MG: Universidade Federal de Viçosa, 2007. 382p.

ALFENAS, A. C. et al. Ralstonia solanacearum em viveiros clonais de eucalipto no Brasil. Fitopatologia Brasileira, v.31, n.4, p.357-366, 2006.

ARAÚJO, J. S. P. et al. Efeito do acibenzolar-Smethyl sobre murcha-bacterina do tomateiro.

Horticultura Brasileira, v.23, n.1, p.5-8, 2005.

COELHO NETO, R. A. et al. Caracterização de isolados de Ralstonia solanacearum obtidos de tomateiros em várzea e em terra firme, no Estado do Amazonas. Fitopatologia Brasileira, v.28, n.4, p.362-366, 2003.

COUTINHO, T. A. et al. First report of bacterial wilt caused by Ralstonia solanacearum on eucalypts in South Africa. Forest Pathology, v.30, n.4, p.205-210, 2000.

DARRASSE, A.; TRIGALET, A.; PRIOR, P. Correlation of aggressiveness with genomic variation in Ralstonia solanacearum Race 1. In: PRIOR, P.; ELPHINSTONE, J. (Ed.). Bacterial wilt disease. molecular and epidemiological aspects. Berlin: Springer-Verlag, 1998. p.89-98.

DIANESE, J. C.; DRISTIG, M. C. G. Screening Eucalyptus selections for resistance to bacterial wilt caused by Pseudomonas solanacearum. In: HARTMAN, G. L.; HAYWARD, A. C. (Ed.). Bacterial wilt. Kaohsiung, Taiwan: ACIAR Proceedings, 1993. p.206-210.
DIANESE, J. C.; DRISTIG, M. C. G.; CRUZ, A. P. Susceptibility to wilt associated with Pseudomonas solanacearum among six species of Eucalyptus growing in equatorial Brazil. Australasian Plant Pathology, v.19, n.3, p.71-76, 1990.

FERREIRA, F. A. et al. Sintomatologia da murcha de Ceratocystis fimbriata em eucalipto. Revista Árvore, v.30, n.2, p.155-162, 2006.

GAVA, C. A. R. et al. Seleção de isolados de estreptomicetos para controle de Ralstonia solanacearum em tomateiro. Pesquisa

Agropecuária Brasileira, v.37, n.10, p.13731380, 2002.

HAYWARD, A. C. Biology and epidemiology of bacterial wilt caused by Pseudomonas solanacearum. Annual Review of Phytopathology, v.29, p.65-87, 1991.

HAYWARD, A. C. Ralstonia solanacearum. In: LEDERBERG, J. (Ed.). Encyclopedia of microbiology. San Diego: Academic Press, 2000. p.32-42.

KADO, E. I.; HESKETT, M. G. Selective media for isolation of Agrobacterium, Corynebacterium, Erwinia, Pseudomonas and Xanthomonas.

Phytopathology, v.60, n.6, p.969-976, 1970.

KELMAN, A. The relationship of pathogenicity in Pseudomonas solanacearum to colony appearance on a tetrazolium medium. Phytopathology, v.44, n.12, p.693-695, 1954.

LI, H.; WU, X. Y. The current status causes and control of forest diseases in Haiman province. Tropical Forestry, v.24, n.1, p.101-103, 1996.

LIN, X. P. et al. The epidemic law of bacterial wilt in Eucalyptus. Journal Central South Forestry University, v.16, n.1, p.49-55, 1996.

LOPES, C. A.; TAKATSU, A. Controle da murcha bacteriana. Fitopatologia Brasileira, v.22, n.1, p.224-225, 1997.

LOPES, C. A. Situação da murcha bacteriana no Brasil. In: Enfermedades bacterianas de la papa. Memórias del taller sobre enfermedades bacterianas de la papa. Brasília: CNPH/EMBRAPA-CIP, 1994.

Revista Árvore, Viçosa-MG, v.38, n.4, p.649-656, 2014 
PRIOR, P.; STEVA, H. Characteristics of strains of Pseudomonas solanacearum from the French West Indies. Plant Disease, v.74, n.1, p.13-17, 1990.

SHI, Z. M. et al. Studies on selection of Eucalyptus for resistance to bacterial wilt and resistance stability. Guangxi Forestry Science, v.29, n.1, p.1-6, 2000.

SUDO, S.; OLIVEIRA, G.H.N.; PEREIRA, A.C. Eucalipto (Eucalyptus sp.) e bracatinga (Mimosa scabrella Penth), novos hospedeiros de Pseudomonas solanacearum E.F. Smith.

Fitopatologia Brasileira, v.8, n.3, p.631, 1983.

TAKATSU, A.; LOPES, C. A. Murcha-bacteriana em hortaliças: avanços científicos e perspectivas futuras de controle. Horticultura

Brasileira, v.15, n.1, p.170-177, 1997.
WU, Q. P.; LIANG, Z. C. Selection of species and provenance of Eucalyptus for resistance to bacterial wilt. Journal South China Agriculture University, v.9, n.1, p.41-45, 1988.

XAVIER, A. A. et al. Resistência de Eucalyptus globulus e Eucalyptus nitens à ferrugem (Puccinia psidii). Revista Árvore, v.31, n.4, p.731-735. 2007.

YABUUCHI, E. et al. Transfer of two Burkholderia and an Alcaligenes species to Ralstonia gen. nov.: proposal of Ralstonia pickettii (Ralston, Palleroni and Douderoff 1973) comb. nov., Ralstonia solanacearum (Smith 1896) comb. nov. \& Ralstonia eutropha (Davis 1969) comb. nov. Microbiology and

Immunology, v.39, n.11, p.897-904, 1995. 